\title{
Palatal Rugae for the Construction of Forensic Identification
}

\author{
Rugas Palatinas en Identificación Forense
}

Li Bing",***; Xiu-Ping Wu**; Yin Feng**; Yu-Jin Wang** \& Hong-Chen Liu*

BING, L.; WU, X. P.; FENG, Y.; WANG, Y. J. \& LIU, H. C. Palatal rugae for the construction of forensic identification. Int. J. Morphol., 32(2):546-550, 2014.

SUMMARY: This study aims to explore the role of palatal rugae pattern in forensic identification by coding of palatal rugae characteristics, and to construct a forensic identification system for oral palatal rugae. One hundred models were included in this study for a systemic coding of palatal rugae pattern based on the shape, quantity, location, and distribution of palatal rugae. Among the involved 100 models, palatal rugae types varied among individuals and palatal rugae pattern was different between men and women, even between two sides in the same individual. Palatal rugae pattern can be used for forensic identification of oral soft tissue and this study proposes a new means for the identification by coding of palatal rugae pattern based on the shape, quantity, location and distribution.

KEY WORDS: Palatal rugae; Identification; Coding.

\section{INTRODUCTION}

Forensic odontological identification by their nature is multidisciplinary team efforts relying on positive identification as well as presumptive or exclusionary methodologies (Acharya \& Sivapathasundharam, 2009). In forensic odontology dentists play a pivotal role in supporting legal and criminal issues (Acharya, 2006).

Personal identification forms an integral part of forensic science, especially when they are dealing with crimes or with mutilated bodies that have undergone damage beyond recognition. Palatal rugae pattern is a forensic identification parameter. In 1889 Allen applied palatal rugae in the identification for the first time. Under the protection of lips, cheeks, tongue, teeth, bones and dentures, palatal rugae can protect against trauma, high temperature and decomposition, and is less susceptible to trauma and injuries, so it plays an important role on forensic identification (Limson \& Julian, 2004). In the human lifetime, the length of palatal rugae may change but the location maintains unchanged. It is generally recognized that the palatal rugae pattern is a permanent line like fingerprints and cheilogramma, it never alters by disease, trauma or chemical corrosion. When other tissue structures are damaged or burning, palatal rugae within the mouth retains complete. Due to unique and diverse features, human palatal rugae attract increasing attention as a new marker in the forensic identification. Growing evidences have focused on the use of human palatal rugae pattern in personal identification.

Palatal rugae pattern is different among each individual, even between the twins (Thomas \& Kotze, 1983). Palatal rugae is mediated by genetic genes, showing various characteristics among population and retains unchanged in each individual. It is also available for forensic identification because it is difficult to counterfeit, but easy to observe and measure. The choice of palatal rugae pattern in forensic identification is highly involved in the palatal rugae quantity, location and distribution. However, objective and standardized evidence concerning the identification methods and indicators are rarely studied. In this study, we conducted a comprehensive coding, statistical analysis and evaluation of palatal rugae pattern, in a broader attempt to establish the identification index and code of palatal rugae and to provide a new means for forensic identification.

\section{SUBJECT AND METHOD}

One hundred patients were recruited from to Department of Prothodontics, Stomatological Hospital of Shanxi Medical University, China from January 2012 to

\footnotetext{
* Department of Stomatology, PLA 301 Hospital, Beijing, China.

** Stomatology Hospital, Shanxi Medical University, Taiyuan, China.
} 
December 2012, including 50 male and 50 female. Inclusion criteria were as follows: 1) Aged more than 20 years; 2) having no history of skull and jaw trauma; 3) having no orthodontic and orthognathic history. Exclusion criteria were as follows: 1) having congenital anomalies/malformations; 2) candidate for orthognathic surgery; 3) being allergic to impression materials; 4) bone and soft tissue protrusion, active lesions; 5) palatal deformity or scars or trauma. This study was conducted in accordance with the declaration of Helsinki. This study was conducted with approval from the Ethics Committee of Stomatological Hospital of Shanxi Medical University. Written informed consent was obtained from all participants.

Model establishment. Each subject involved in this study had signed informed consents prior to experimentation. The impression was prepared using perforated stainless steel tray filled with silicone rubber impression materials. Then dental anhydrite was dissolved in water according to certain proportions and filled into the impression, thus obtaining the models. The success of the impression model is defined upon the following appearance: 1) models can accurately reflect the fine anatomical structure of oral tissue, showing stable dimension, high accuracy, clear boundary and no surface defects such as bubbles and gypsum blocks; 2) models possess certain shape and thickness to ensure the experimental requirement; 3 ) models are smooth on the surface and easy to mold. Its high surface hardness can withstand the wearing during the experiment and great compression strength prevents breakage and damage.

Palatal rugae types. The letters given to each rugae based on its form is depicted in Table I and Figure 1.

Coding method. The palatal rugae pattern on the model was depicted using 2B graphite pencils and encoded based on the Santos classification (Fig. 2). Coding principles are as follows: 1) The classification and coding are performed according to palatal rugae quantity, location, distribution and other features; 2) Palatal rugae coding sequence is first at the right side and then at the left side, first at the anterior
Table I. Palatal rugae pattern classification.

\begin{tabular}{llc}
\hline Palatal rugae patt em & Features & Abbreviations \\
\hline Angle & Angle lines & $\mathrm{A}$ \\
Anomaly & Irregular lines & $\mathrm{An}$ \\
Bifurcated & Bifurcated lines & $\mathrm{B}$ \\
Curve & Curve lines & $\mathrm{C}$ \\
Interrupt & Interrupted lines & $\mathrm{I}$ \\
Line & Straight lines & $\mathrm{L}$ \\
Circle & Circled lines & $\mathrm{O}$ \\
Point & Points & $\mathrm{P}$ \\
Sinuous & Sinuous lines & $\mathrm{S}$ \\
Trifurc ated & Trifurcated lines & $\mathrm{T}$ \\
\hline
\end{tabular}

part and then at the posterior part; 3) The right anterior palatal rugae is termed by the capitalized English letters of this palatal rugae type; 4 ) The right and left codes are connected using a dash.

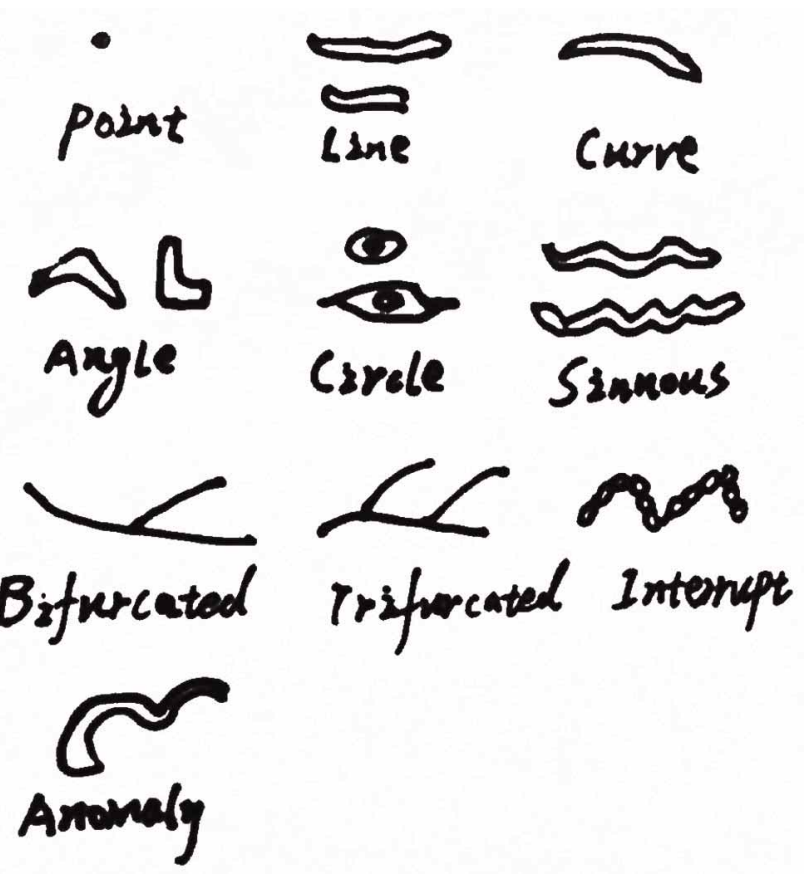

Fig. 1. Palatal rugae pattern classification.

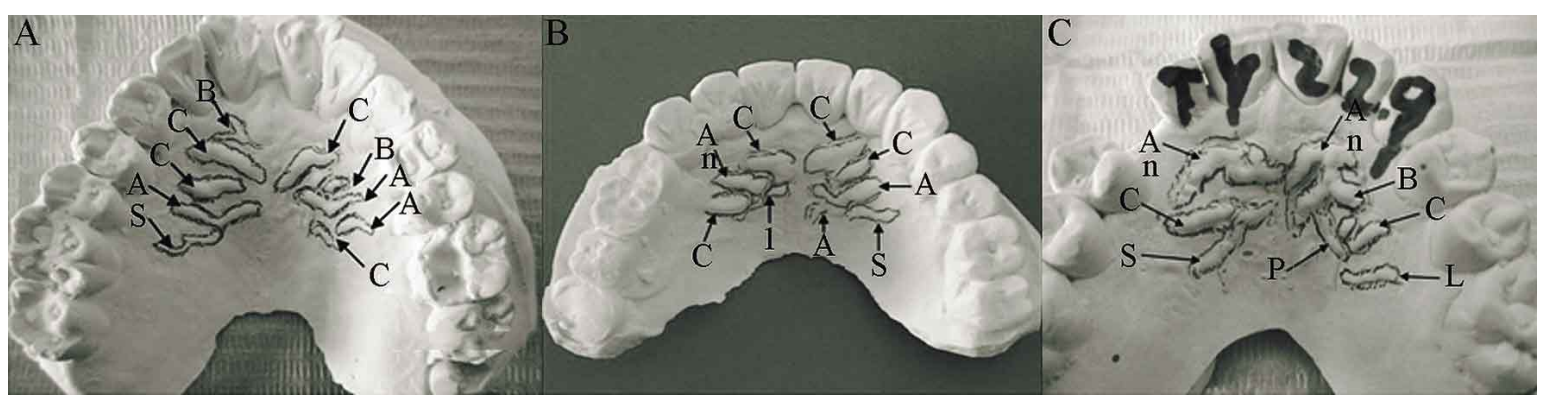

Fig. 2. Palatal rugae code examples. A: Palatal rugae code: BCCAS-CBAAC. B: Palatal rugae code: CAnCI-CCASA. C: Palatal rugae code: AnCS-AnBCLP. 


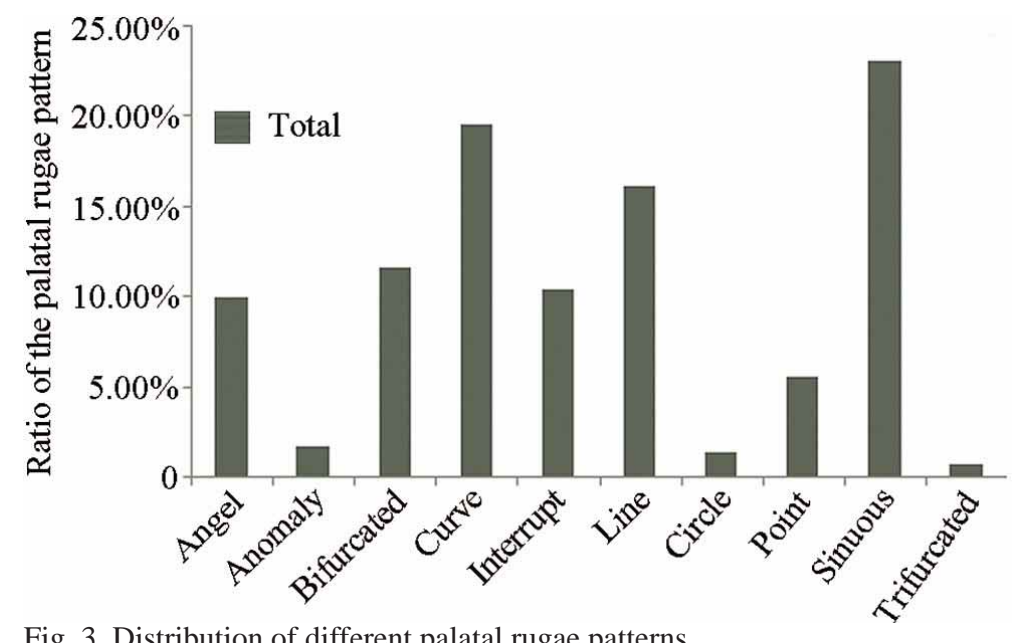

Fig. 3. Distribution of different palatal rugae patterns.

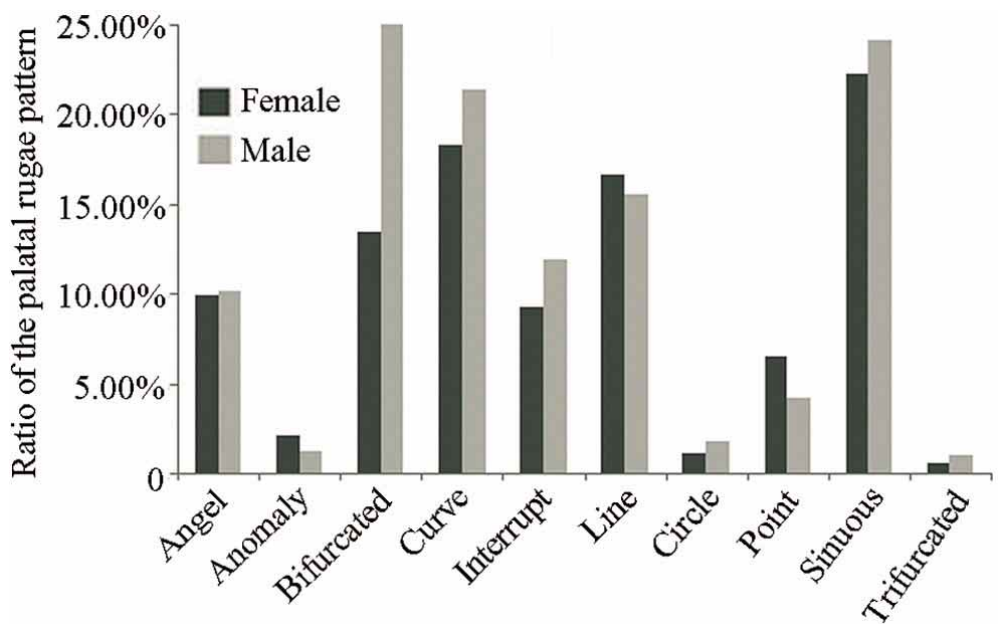

Fig. 4. Distribution of different palatal rugae patterns in men and women.

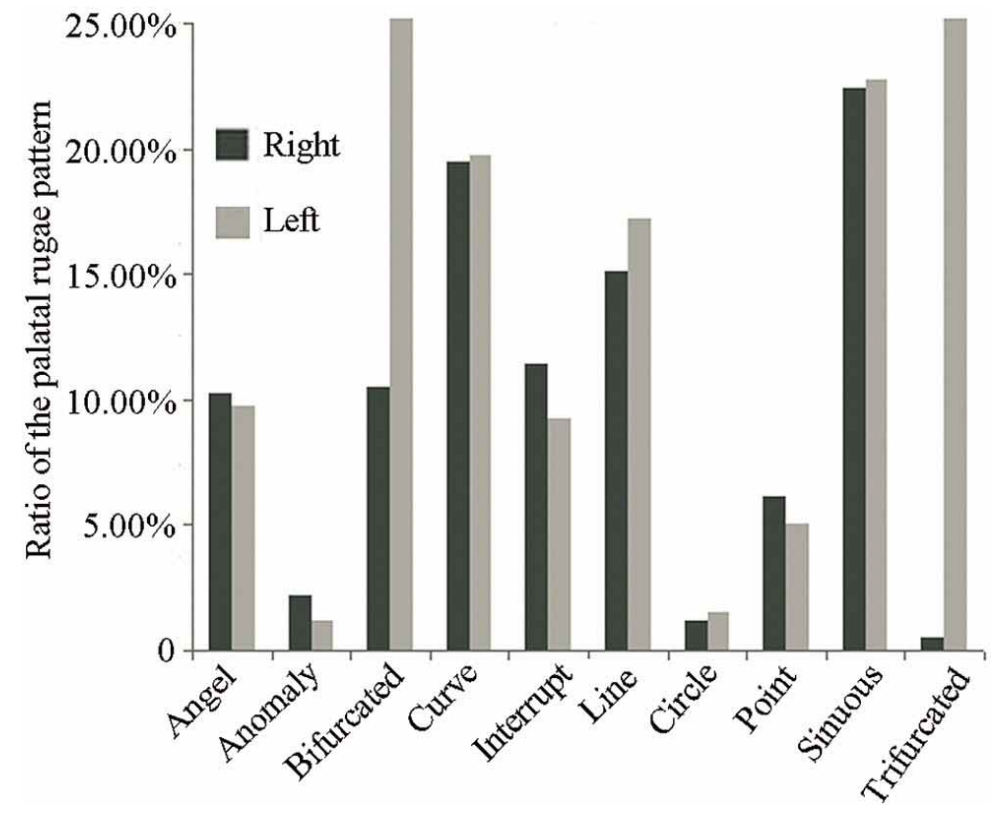

Fig. 5. Distribution of different palatal rugae patterns at the left and right sides.
Statistical analysis. The coding of palatal rugae pattern in the involved 100 subjects was subject to a statistical analysis. The analysis content included the proportion of different types of palatal rugae in the total palate rugae; proportion of different types of palatal rugae in men and women; proportion of different types of palatal rugae in maxillary palate.

\section{RESULTS}

Proportion of different types of palatal rugae in 100 patients. The palatal rugae types varied among the involved 100 models. Angle $9.98 \%$, Anomaly $1.72 \%$, Bifurcated $11.58 \%$, Curve $19.58 \%$, Interrupt $10.35 \%$, Line $16.13 \%$, Circle $1.36 \%$, Point $5.54 \%$, Sinuous $23.03 \%$, Trifurcated $0.74 \%$. The curve type accounted for the higher percentage $(23.03 \%)$, while the trifurcated type occupied the lowest proportion (0.74\%; Fig. 3).

Proportion of different types of palatal rugae in men and women. The proportion of different types of palatal rugae in men and women (women: Angle 9.87\%, Anomaly $2.10 \%$, Bifurcated 13.45\%, Curve 18.28\%, Interrupt $9.24 \%$, Line $16.60 \%$, Circle $1.05 \%$, Point $6.51 \%$, Sinuous $22.7 \%$, Trifurcated $0.63 \%$. Men: Angle $10.12 \%$, Anomaly $1.19 \%$, Bifurcated $8.93 \%$, Curve $21.43 \%$, Interrupt $11.91 \%$, Line $15.48 \%$, Circle $1.79 \%$, Point $4.17 \%$, Sinuous $24.11 \%$, Trifurcated $0.89 \%$ ). The sinuous and curve types were dominant in men and women (women: sinuous $22.7 \%$, curve $18.28 \%$; men: sinuous $24.11 \%$, curve $21.43 \%$; Fig. 4 ).

Proportion of different types of palatal rugae in the left and right sides. The quantity and distribution of palatal rugae pattern were asymmetrical between the left and right sides (right: Angle 42, 10.22\%; Anomaly 9, 2.19\%; Bifurcated 43, 10.46\%; Curve 80, 19.47\%; Interrupt 47, 11.45\%; Line 62, 15.09\%; Circle 5, 1.22\%; Point 25, 6.08\%; Sinuous 96, 22.36\%; Trifurcated 2, 0.49\%. left: Angle 39, $9.73 \%$; Anomaly 5, $1.25 \%$; Bifurcated 51, 12.72\%; Curve 79, 19.70\%; Interrupt 37, 9.23\%; Line 69, 17.21\%; Circle 6, 1.50\%; Point 20, 4.99\%; Sinuous 91, 22.69\%; Trifurcated 4, 1.00\%; Fig. 5). 


\section{DISCUSSION}

Palatal rugae are mainly used to determine a person's identity, also termed forensic identification. The uniqueness and stability of palatal rugae allow its applications for forensic identification. Palate is fornix-shaped and trapped by dental arch. There is a thin, longitudinal mucosal protrusion in the median line of hard palate, called median palatal suture. Palatal rugae locate in advance of the hard palate, it is actually three-seven soft tissue ridges radially evoked from incisive papillae (or palatal papillae) and median palatal suture, and its shape is irregular and asymmetric (Hauser et al., 1989; Pretty, 2007; Ohtani et al., 2008; Sharma et al., 2009; Virdi et al., 2010). Palatal rugae protrusions are mainly dense connective tissue, and palatal rugae development can be triggered by local epithelial cell proliferation. Palatal rugae pattern is determined by continuous fibers concentrically around the palate. Then, fibroblasts and collagen fibers accumulate in the thickening connective tissue below epithelial cells, showing different directions. The core fibers in the human palatal rugae contain many factors to maintain the palatal shape. The maincomponent of palatal rugae is hydrophilic glycosaminoglycan, which promotes tissue swelling and helps maintain palatal pattern (English et al., 1988; Whittaker, 1994; Damstra et al., 2009; Hermosilla Venegas et al., 2009; Mittal et al., 2013).

Under the protection of lips, cheeks, tongue, teeth, bones and dentures, palatal rugae can protect against trauma, high temperature and decomposition, and is less susceptible to trauma and injuries (Shetty et al., 2005; Acharya et al., 2011). In the human lifetime, the length of palatal rugae may change but the location maintains unchanged (Bharath et al., 2011). It is generally recognized that the palatal rugae pattern is permanent like fingerprints and cheilogramma, it never alters by disease, trauma or chemical corrosion. Palatal rugae pattern is unique among individuals, even between twins. Palatal rugae pattern is mediated by genetic genes, showing various characteristics among population and retains unchanged in each individual. It is also available for forensic identification because it is difficult to counterfeit, but easy to observe and measure. The choice of palatal rugae pattern in forensic identification is highly involved in the palatal rugae quantity, location and distribution (Chatterjee \& Khanna, 2011).

The results of this study found that, all 100 subjects had different and unique palatal rugae patterns. No case exhibited the similar palatal rugae pattern with others, and the pattern was not bilaterally symmetric in one case. Therefore, the uniqueness of palatal rugae patterns contributes to personal identification, which was consistent with previous studies. Palatal rugae pattern is the mixture of various forms, rather than one simple form. Curve type is the most commonly observed pattern, followed by line and sinuous types. Our findings differ from the results of Pretty and Ohtani (Hemanth et al., 2010), who observed different types of palatal rugae. Therefore, we speculate that palatal rugae patterns are targeted at specific population and provide practical evidence for population differentiation.

The curve and sinuous types are dominantly observed in men or women (men: curve $21.43 \%$, sinuous $24.13 \%$; women: curve $18.28 \%$, sinuous $22.7 \%$ ). It is also noted that, the men presented more palatal rugae than the women. Furthermore there were more palatal rugae at the right side compared with the left side, which potentially due to different oral environments.

Palatal rugae pattern is strongly recommended in the forensic identification due to its uniqueness, low cost, simplicity and reliability. By using palatal rugae patterns, we can distinguish the features among populations, because palatal rugae pattern and distribution are unique in each person (Damstra et al.). However, large-scale comparative study concerning different races, family members, and monozygotic twins is urgently needed in the future. In addition, we should propose uniform standards and procedures for palatal rugae pattern collection, recording and computer analysis, which is conducive to the establishment of palatal rugae system in forensic identification.

BING, L.; WU, X. P.; FENG, Y.; WANG, Y. J. \& LIU, H. C. Rugas palatinas en identificación forense. Int. J. Morphol., 32(2):546$550,2014$.

RESUMEN: Este estudio tuvo como objetivo explorar el patrón de rugas palatinas en la identificación forense mediante la codificación de las características de éstas. Además se elaboró un sistema de identificación forense. Fueron incluidos cien modelos para una codificación sistemática del patrón de rugas palatinas basado en su forma, cantidad, ubicación y distribución. En todos los modelos se identificó una variación entre los individuos y en el patrón entre hombres y mujeres. El patrón de rugas palatinas puede ser utilizado para la identificación forense de tejido blando oral y este estudio propone un método nuevo para codificarlas.

PALABRAS CLAVE: Rugas palatinas; Identificación; Codificación. 


\section{REFERENCES}

Acharya, A. B. Teaching forensic odontology: an opinion on its content and format. Eur. J. Dent. Educ., 10(3):137-41, 2006.

Acharya, A. B.; Prabhu, S. \& Muddapur, M. V. Odontometric sex assessment from logistic regression analysis. Int. J. Legal Med., 125(2):199-204, 2011.

Acharya, A. B. \& Sivapathasundharam, B. Forensics Odontology. In: Rajendran, R. \& Sivapathasundharam, B. (Eds.). Shafer's Textbook of Oral Pathology. $6^{\text {th }}$ ed. Noida, Elsevier, 2009. pp.87199.

Bharath, S. T.; Kumar, G. R.; Dhanapal, R. \& Saraswathi, T. Sex determination by discriminant function analysis of palatal rugae from a population of coastal Andhra. J. Forensic Dent. Sci., $3(2): 58-62,2011$

Chatterjee, S. \& Khanna, M. Dimensional analysis of various rugae patterns in north Indian population subset. J. Forensic Dent. Sci., 3(2):86-8, 2011.

Damstra, J.; Mistry, D.; Cruz, C. \& Ren, Y. Antero-posterior and transverse changes in the positions of palatal rugae after rapid maxillary expansion. Eur. J. Orthod., 31(3):327-32, 2009.

English, W. R.; Robison, S. F.; Summitt, J. B.; Oesterle, L. J.; Brannon, R. B. \& Morlang, W. M. Individuality of human palatal rugae. J. Forensic Sci., 33(3):718-26, 1988.

Hauser, G.; Daponte, A. \& Roberts, M. J. Palatine rugae. J. Anat., 165(1):237-49, 1989.

Hemanth, M.; Vidya, M.; Shetty, N. \& Karkera, B. V. Identification of individuals using palatal rugae: Computerized method. $J$. Forensic Dent. Sci., 2(2):86-90, 2010.

Hermosilla Venegas, V.; San Pedro Valenzuela, J.; Cantin Lopez, M. \& Suazo Galdames, I. C. Palatal rugae: systematic analysis of its shape and dimensions for use in human identification. Int. J. Morphol., 27(3):819-25, 2009.

Limson, K. S. \& Julian, R. Computerized recording of the palatal rugae pattern and an evaluation of its application in forensic identification. J. Forensic Odontostomatol., 22(1):1-4, 2004.

Mittal, L.; Narang, R.; Saha, S. \& Saha, S. Palatal rugoscopy. Establishing identity. Indian J. Contemp. Dent., 1(1):58-61, 2013.

Ohtani, M.; Nishida, N.; Chiba, T.; Fukuda, M.; Miyamoto, Y. \& Yoshioka, N. Indication and limitations of using palatal rugae for personal identification in edentulous cases. Forensic Sci. Int., 176(1):178-82, 2008.

Pretty, I. A. Forensic dentistry: 1. Identification of human remains. Dent. Update, 34(10):621-2, 624-6, 629-30, 2007.
Sharma, P.; Saxena, S. \& Rathod, V. Comparative reliability of cheiloscopy and palatoscopy in human identification. Indian J. Dent. Res., 20(4):453-7, 2009.

Shetty, S. K.; Kalia, S.; Patil, K. \& Mahima, V. G. Palatal rugae pattern in Mysorean and Tibetan populations. Indian J. Dent. Res., 16(2):51-5, 2005.

Thomas, C. J. \& Kotze, T. J. The palatal ruga pattern in six southern African human populations. Part II: Inter-racial differences. $J$. Dent. Assoc. S. Afr., 38(3):166-72, 1983.

Virdi, M.; Singh, Y. \& Kumar, A. Role of palatal rugae in forensic identification of the pediatric population. Internet J. Forensic Sci., 4(2):45-7, 2010.

Whittaker, D. K. An introduction to forensic dentistry. Quintessence Int., 25(10):723-30, 1994.

Correspondence to:

Hong-Chen Liu

Department of Stomatology

PLA 301 Hospital

28 Fuxing Road, Beijing 100853

CHINA

Email: hongchenliucn@163.com

Received: 25-12-2013

Accepted: 31-03-2014 